\title{
Experimental Analysis of Performance of Heat Exchanger with Plate Fins and Parallel Flow of Working Fluids
}

\author{
Drilon Meha*, Arben Avdiu, Fejzullah Krasniqi, Ali Muriqi, Xhevat Berisha \\ Faculty of Mechanical Engineering, University "Hasan Prishtina”, Pristina, Kosovo \\ Email: *drilon.meha@uni-pr.edu
}

How to cite this paper: Meha, D., Avdiu, A., Krasniqi, F., Muriqi, A. and Berisha, X. (2017) Experimental Analysis of Performance of Heat Exchanger with Plate Fins and Parallel Flow of Working Fluids. World Journal of Engineering and Technology, 5, 435-444.

https://doi.org/10.4236/wjet.2017.53038

Received: May 31, 2017

Accepted: July 17, 2017

Published: July 20, 2017

Copyright $\odot 2017$ by authors and Scientific Research Publishing Inc. This work is licensed under the Creative Commons Attribution International License (CC BY 4.0).

http://creativecommons.org/licenses/by/4.0/

(c) (i) Open Access

\begin{abstract}
Heat exchangers are devices in which heat is transferred from one fluid to another fluid as a result of temperature difference. Heat exchanger presented in the current paper in which inside the tubes flows water, but outside the tubes flows air aims to enable cooling of circulating water, which serves to cool the engine of a machine. Such exchangers find application in the automotive industry as well as heating and cooling equipment and HVAC systems etc. The surface of the heat exchanger by the air side always tends to be much larger using surface fins in order to facilitate equalization of thermal resistance for both sides of the heat exchanger, because the rate of transmission of heat from the water side is much greater. Furthermore, the paper will present analytical and experimental studies involved for determination of performance of plate-fin heat exchanger for various flows of working fluids in order to get the highest values of performances i.e.: overall heat transfer coefficient $U$, efficiency of heat exchanger $\varepsilon$, maximal and real heat transferred, pressure drop, air velocity and Reynolds number from the air side of heat exchanger etc. The present scientific paper is based on the fact that from the experimental model made for laboratory conditions, conclusions are derived that can be used during installation of such heat exchanger on certain machines in order to predict their performance.
\end{abstract}

\section{Keywords}

Heat Exchanger, Heat Transfer, Fins Surfaces, Single Phase, Plate Fins, Performance

\section{Introduction}

Heat exchanger air-water, applied to the current paper, due to the flow of fluids in the same direction is called the heat exchanger with the parallel flow [1]. 
Regarding the working fluids mixtures, the same heat exchanger is called with mixers along exchanger from the air side, and without mixture from the water side [1]. In such heat exchangers fins surfaces from the air side, which have found more applications are tubular and rectangular ones [1] [2]. The overall efficiency of heat exchangers with fins surfaces is influenced by many factors such as the surface material of heat exchangers, fluid flows, placing distance of surfaces fins, surfaces number of fins and fluid types, flow direction etc. Fins surfaces are usually placed outside the tubes, but there are some applications when they are placed inside the tubes [1]. Most of the research papers in the analysis of plate fins heat exchangers are based on pressure drop and heat transfer characteristics. A heat exchanger with plate fins surfaces consists of plates from the air side instead of tubes to separate the hot and cold water. In 1930's plate heat exchangers are used to meet the hygienic demands of the food industry. These days plate fins heat exchangers find applications in wide range of fields as power generation, heating, ventilation and air conditioning systems, treatment of waste heat, gas production, chemical industry, pharmaceuticals, food industry etc. A method which provides an ideal platform for studying the performance of plate fins heat exchanger with miscible and immiscible systems was developed by M. Thirumarimurugan [3]. An experimental investigation for laboratory conditions is developed by Alur [4] in order to test heat transfer and pressure drop characteristics for a plate fin heat exchanger with the counter flow. Nabadi [5] has analyzed a numerical investigation of pressure drop and heat transfer in a heat exchanger that was designed with the different shape of pin fins.

The purpose of this paper is to determine the optimal operation of the platefin heat exchanger for the various flow of working fluids in order to achieve the highest values of performance.

The experimental set up in this investigation consists of a parallel flow heat exchanger. Changing the airflow along the tunnel is done by a variable speed axial fan, the values of which are measured by a differential micromanometer. At the exit of the tunnel, the air is warmed by receiving heat from the water flowing inside the tubes in the same direction. Water flows are provided by a circulating pump, where the amount of water in the system is measured by a rotameter placed at the exit of hot water. The heat exchanger's effectiveness is calculated for different values of the flow rate between working fluids. The temperature measurements are read on electrical control panel display. Fins surfaces analyzed in the current paper, for heat exchanger air-water are rectangular.

Therefore, the results of the heat transfer and the pressure drop characteristics in function of changing the flow of working fluids are presented below.

\section{Thermal Analysis of Heat Exchangers with Parallel Flow}

The efficiency of the heat exchanger with parallel flow of working fluids is calculated by the expression:

$$
\varepsilon=\frac{1-\mathrm{e}^{-N T U(1+R)}}{(1+R)}
$$


The overall heat transfer coefficient, determined experimentally, is derived from the basic equation of heat transferred:

$$
U_{\exp }=\frac{\dot{Q}_{\exp }}{A \cdot L T M D}
$$

$\dot{Q}_{\text {exp }},[\mathrm{W}]$-experimental heat transferred;

$A,\left[\mathrm{~m}^{2}\right]$-overall surface of heat transfer;

Logarithmic mean temperature difference for parallel flow of working fluids is calculated by the expression:

$$
L T M D=\frac{\left(T_{h, i}-T_{c, i}\right)-\left(T_{h, o}-T_{c, o}\right)}{\ln \frac{\left(T_{h, i}-T_{c, i}\right)}{\left(T_{h, o}-T_{c, o}\right)}}
$$

$T_{h, i n},\left[{ }^{\circ} \mathrm{C}\right]$ - hot fluid temperature at the entrance of heat exchanger;

$T_{h, o},\left[{ }^{\circ} \mathrm{C}\right]$ - hot fluid temperature at the exit of heat exchanger;

$T_{c, i n},\left[{ }^{\circ} \mathrm{C}\right]$-cold fluid temperature at the entrance of heat exchanger;

$T_{c, o},\left[{ }^{\circ} \mathrm{C}\right]$-cold fluid temperature at the exit of heat exchanger;

The ratio of the thermal capacity of working fluids is given by the expression:

$$
R=\frac{c_{c} \cdot \dot{m}_{c}}{c_{h} \cdot \dot{m}_{h}}
$$

$C_{c},[\mathrm{~kJ} / \mathrm{kg} \mathrm{K}]$-specific heat capacity of cold fluid:

$c_{h},[\mathrm{~kJ} / \mathrm{kg} \mathrm{K}]$-specific heat capacity of hot fluid:

$\dot{m}_{h},[\mathrm{~kg} / \mathrm{s}]$ - flow mass of hot fluid;

$\dot{m}_{c},[\mathrm{~kg} / \mathrm{s}]$ — flow mass of cold fluid;

The number of transmission units:

$$
N T U=\frac{U_{\text {exp }} \cdot A}{C_{\min }}
$$

$U_{\text {exp }},\left[\mathrm{W} / \mathrm{m}^{2} \mathrm{~K}\right]$ - the overall heat transfer coefficient determined experimentally;

$C_{\min }=\min \left(C_{h}, C_{c}\right),[\mathrm{kJ} / \mathrm{kg} \mathrm{K}]$-minimal thermal capacity of fluid;

The maximum temperature difference in a heat exchanger:

$$
\Delta T_{\max }=T_{h, i n}-T_{c, i n}
$$

The maximum heat transferred in a Heat exchanger is:

$$
\dot{Q}_{\max }=C_{\min } \cdot \Delta T_{\max }
$$

Accordingly, the efficiency of heat exchanger water-air with plate fins surfaces is:

$$
\varepsilon=\frac{\dot{Q}_{\text {exp }}}{\dot{Q}_{\max }}
$$

The total heat transferred between working fluids with parallel flows in a heat exchanger with plate fins surfaces, is calculated by the following equation:

$$
\dot{Q}_{\exp }=\varepsilon \cdot \dot{m}_{c} \cdot c_{c} \cdot \Delta t_{\max }
$$

From the expression of the number of transmission units, we can extract the 
value of the product $U^{*} A$ :

$$
U_{\exp } \cdot A=c_{\min } \cdot \dot{m}_{\min } N T U
$$

\section{Pressure Drop by the Air Side of Heat Exchangers with Plate Fins Surfaces}

The maximum pressure drop is considered as one of main the design specifications. If the pressure drop reaches the maximum values higher than allowed, additional fins surface should not be added.

For the description of pressure drop is necessary to apply for non-dimensional numbers: Staton, Prandtl, and Reynolds:

$$
S_{t}=\frac{\alpha}{G \cdot c_{p}}, \quad P_{r}=\frac{c_{p} \cdot \mu}{\lambda}, \quad R_{e}=\frac{G \cdot D_{h}}{\mu}
$$

$\mu,[\mathrm{Pa} \mathrm{s}]$-dynamic viscosity of fluid;

$D_{h},[\mathrm{~m}]$ - hydraulic diameter;

$\lambda,[\mathrm{W} / \mathrm{mK}]$ - thermal conductivity of fluid;

$G,\left[\mathrm{~kg} / \mathrm{m}^{2} \mathrm{~s}\right]$ 一the mass velocity or mass flux;

$\alpha,\left[\mathrm{W} / \mathrm{m}^{2} \mathrm{~K}\right]$ - heat transfer coefficient with convection;

$c_{p},[\mathrm{~kJ} / \mathrm{kg} \mathrm{K}]$-specific heat capacity of the fluid

The hydraulic diameter is defined as four times the flow passage volume divided by the total heat transfer area:

$$
D_{h}=\frac{4 \cdot A}{P}=4 \cdot \frac{L \cdot A_{\min }}{A}
$$

$P,[\mathrm{~m}]$-perimeter of section; $A_{\min },\left[\mathrm{m}^{2}\right]-$ minimum flow area.

The pressure drop from the air side in heat exchangers with Plate fins surfaces is given by expression [2]:

$$
\Delta p=\frac{G^{2}}{2 \cdot \rho_{b}} \cdot\left[\left(k_{c}+1-\sigma^{2}\right)+2 \cdot\left(\frac{\rho_{b}}{\rho_{j}}-1\right)+f \cdot \frac{A}{A_{\min }} \cdot \frac{\rho_{b}}{\rho}-\left(1-k_{e}-\sigma^{2}\right) \cdot \frac{\rho_{b}}{\rho_{j}}\right]
$$

$k_{c}, k_{e}$-coefficient of pressure losses in the entrance and exit of the heat exchanger [1].

$\dot{m},[\mathrm{~kg} / \mathrm{s}]$ - flow mass of air;

$\rho,\left[\mathrm{kg} / \mathrm{m}^{3}\right]$ - The average density of air;

$\rho_{b}, \rho_{j},\left[\mathrm{~kg} / \mathrm{m}^{3}\right]$-fluid density in the entrance and exit of heat exchanger;

$f$-The coefficient of friction.

The coefficient of friction from the air side of plate fin heat exchanger (f) is calculated by the expression:

$$
f=0.064 \cdot(\mathrm{Re})^{-0.2}
$$

Where: $\sigma=A_{\min } / A$, the minimum surface free flow/frontal area

$\frac{A}{A_{\min }}=\frac{4 \cdot L}{D_{h}}$, (total area of heat transfer/minimum flow area)

$L,[\mathrm{~m}]$-distance of flow in heat exchanger;

$L \cdot A_{\min },\left[\mathrm{m}^{3}\right]-$ minimal volume of free flow; 
$A,\left[\mathrm{~m}^{2}\right]$ - the overall surface of heat transfer.

The mass velocity or mass flux is defined as:

$$
G=\frac{\rho \cdot w_{\infty} \cdot A}{A_{\min }}=\frac{\rho \cdot w_{\infty}}{\sigma}
$$

$w_{\infty},[\mathrm{m} / \mathrm{s}]$-average velocity of air,

The average density of the air:

$$
\rho=\frac{1}{2} \cdot\left(\frac{1}{\rho_{b}}+\frac{1}{\rho_{j}}\right)
$$

\section{Testing Unit of Water/Air Heat Exchanger Installed in a Sheet Steel Tunnel}

This model unit presented in Figure 1 makes possible to study the operation of water/air heat exchanger, made of aluminum with round expanded pipes, installed in a painted sheet steel tunnel.

The circulation of air is ensured by a variable speed fan, Four Pt100 heat resistors, connected to a digital instrument, are placed at suitable measuring points in the system. The air flows through the test unit 1 (tunnel) by means of the axial fan 2 , and a differential micromanometer 3 , interlocked with a calibrated flange, makes it possible to measure the rate of flow from the fins plate surfaces.

On the other hand, the water with temperature $T_{1}$ enters into Heat Exchanger and leaves it with temperature $\mathrm{T}_{2}$. Further, water is sent to the water feed tank 4, where the water level measurement is performed by float type valve 5 . By means of the three speed circulating pump 7 the water is sent to the electric heater 10 in which the water of temperature is increased to $T_{1}$. Water flow measurement is carried out by a flow meter 11 .
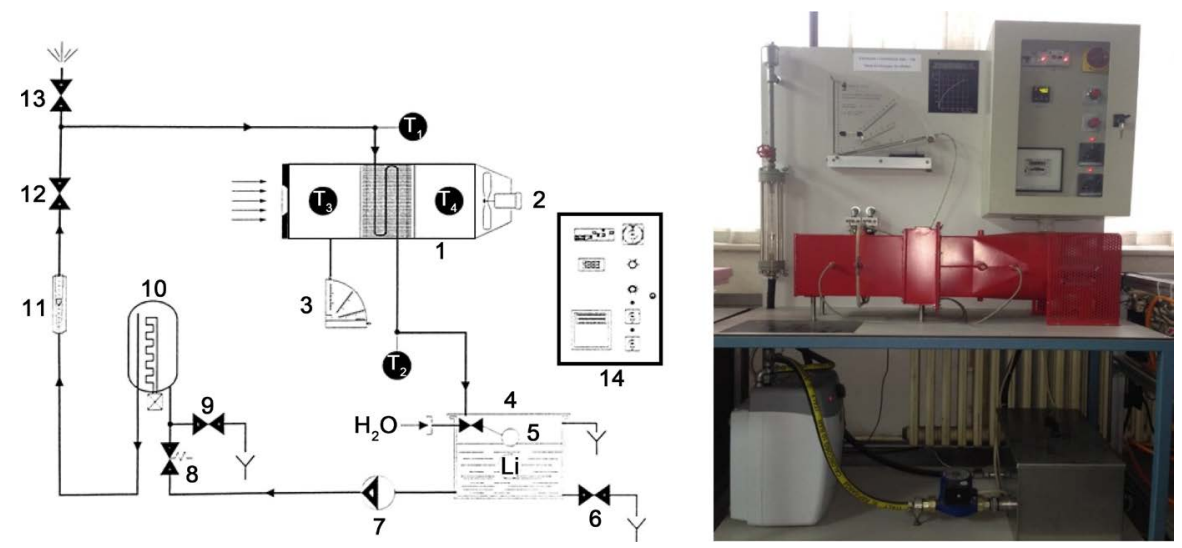

Figure 1. 1. Testing tunnel with calibrated diagram and water/air heat exchanger, 2. Electrically operated variable speed axial fan, 3 . Differential micromanometer, 4 . Water circulation and feed tank, 5. Float type valve, 6 . Tank discharge valve, 7 . Three-speed circulation pump, 8. Safety valve for boiler, 9. Boiler discharge valve, 10. Electric boiler, 11. Flowmeter (0 to 300) [1/h], 12. Flow control valve, 13. Air bleed valve, 14. Electrical control panel, LI. Level indicator, $\mathrm{T}_{1}$. Water temperature at the inlet to the heat exchanger, $\mathrm{T}_{2}$. Water temperature at the outlet of the heat exchanger, $\mathrm{T}_{3}$. Air temperature at the inlet to the heat exchanger, $\mathrm{T}_{4}$. Air temperature at the outlet of the heat exchanger. 
The valves $12,13,18,19,6$ serve to maintain the water circuit under the permissible norms in order to perform a normal operation of the heat exchanger.

\section{Experimental Analysis of Performance of Plate-Fin Heat Exchanger}

Experimental analysis of performance for the current heat exchanger is made in the device shown in Figure 1. In order to highlight the impacts of changing flow of working fluids, the following diagrams are presented bellow as: logarithmic mean temperature difference, efficiency of heat exchanger, real and maximal heat transferred in heat exchanger, the overall heat transfer coefficient, pressure drop, air velocity, Reynolds number from the air side of heat exchanger. Although, the physical properties of the working fluids, which are presented in the Table 1 with a fixed values, during the calculation they are taken into consideration being changed with temperature, even though the effect of temperature on physical properties has little or there was no effect on the performance of heat exchanger.

As seen from Figure 2(a), the increase in the flow of hot water from 30 to 40 [1/h] causes a decrease in LMTD, while the increase in flow from 40 to 200 [1/h] causes a slower growth of LMTD. The maximum change of LMTD for variable flow mass of hot water (for unchanged air flow $40[\mathrm{~kg} / \mathrm{h}]$ ) has resulted to be equal with $16.42^{\circ} \mathrm{C}-13.19^{\circ} \mathrm{C}=3.23^{\circ} \mathrm{C}$. Similarly, in Figure 2(b). LMTD is displayed with the changing of air flow, which flows through the heat exchanger from 40 to $220[\mathrm{~kg} / \mathrm{h}]$, but for unchanged hot water flow $100[1 / \mathrm{h}]$. From fig. 3 b.are seen the fluctuations of LMTD as a result of flow mass of air changing. This change has caused the maximum difference of LMTD from $16.23^{\circ} \mathrm{C}-$ $14.23^{\circ} \mathrm{C}=2^{\circ} \mathrm{C}$. From comparisons between Figure 2(a) and Figure 2(b), we came to the conclusion that the effect of changing the water flow $\left(3.23^{\circ} \mathrm{C}\right)$ is more pronounced than the change of air flow $\left(2^{\circ} \mathrm{C}\right)$ to the LMTD. From Figure $3(\mathrm{a})$, it is seen that for unchanged hot water flow $100[1 / \mathrm{h}]$ when the air flows through the heat exchanger with fins surfaces is increased by the fan, in that case, the overall efficiency of the heat exchanger is reduced. This is due to the short contact between the working fluids and the inability that air mass flow to absorb that heat. The same happens during the drive of a car when the velocity is too large in that case, it causes the engine to warm up, thus preventing the cooling.

Therefore, for such applications, the Heat Exchangers should be used with phase changes of working fluids. The opposite occurs in Figure 3(b), when the airflow generated by the fan remains unchanged, while changes the flow of hot water through the three-speed circulation pump. Because of the air flows slowly, then

Table 1. Physical properties of working fluids along the Plate-fin heat exchanger.

\begin{tabular}{cccccccccc}
\hline $\mathbf{k}$ & $\mathbf{k}$ & $\mathrm{Cp}$ & $\mathrm{Cp}$ & $\mu$ & $\mu$ & $\rho$ & $\rho$ & $\operatorname{Pr}$ & $\operatorname{Pr}$ \\
\hline W/mK & $\mathrm{W} / \mathrm{mK}$ & $\mathrm{J} / \mathrm{kgK}$ & $\mathrm{J} / \mathrm{kgK}$ & $\mathrm{Pa}^{*} \mathrm{~s}$ & $\mathrm{~Pa}^{*} \mathrm{~s}$ & $\mathrm{~kg} / \mathrm{m}^{3}$ & $\mathrm{~kg} / \mathrm{m}^{3}$ & - & - \\
\hline Water & Air & Water & Air & Water & Air & Water & Air & Water & Air \\
\hline 0.65 & 0.03 & 4065.85 & 1007.25 & 0.0005 & 0.000019 & 985.4 & 1.12 & 3.08 & 0.71 \\
\hline
\end{tabular}



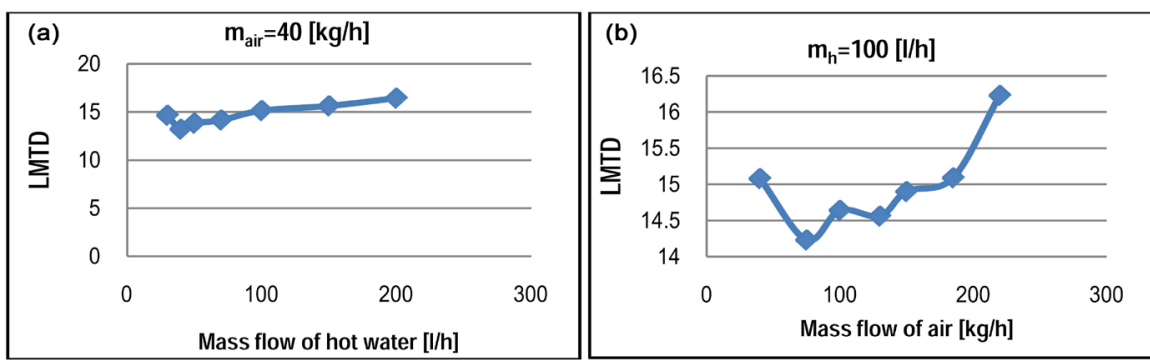

Figure 2. Graphical presentation of logarithmic mean temperature difference (LMTD method), by changing the mass flow of working fluids in a heat exchanger.

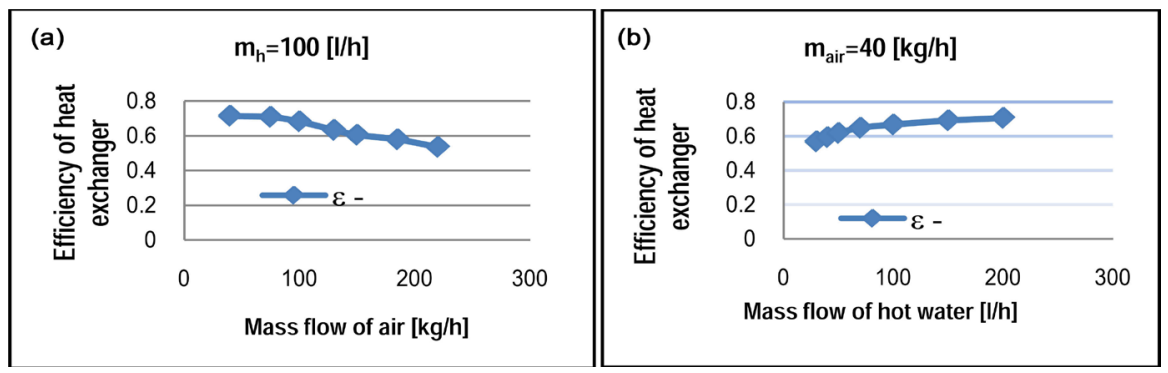

Figure 3. Graphical presentation of the efficiency of the heat exchanger (plate fins heat exchanger) determined experimentally by changing the flow mass of working fluids.

it receives more heat and consequently the efficiency of Heat exchanger increases.

Figure 4(a) shows the actual and maximal heat transmitted, measured experimentally in laboratory conditions, with variable air flow and constant flow ofhot water. In Figure 4(a) with the red line is presented the heat that air receives by changing the flow mass of air from 293 [W] up to 1188 [W], while with blue line is presented the maximum heat that air can absorb.

Similarly, another diagram Figure 4(b) was constructed when the hot water flow was changed $\left(\mathrm{m}_{\text {air }}=\right.$ const), but in this case, the heat absorbed by air flow was too low and reached the values from 59 [W] to $81[\mathrm{~W}]$.

From Figure 5(a), it can be seen that the increase in the air flow by the air side with fins surfaces has a much more significant effect on the overall heat transfer coefficient than the change in the flow of hot water, which after $50[1 / \mathrm{h}]$ has almost constant value (Figure 5(b)).

Figure 6 shows the pressure drop by the fins surfaces applying the Equation (13). The highest experimental value of the pressure drop has resulted in 1.5 [bar] and for these high values of airflow undesirable noise was produced.

With the change of mass flow of air with the fan, the air velocity on the side with fins surfaces has been linearly changed (see Figure 7). Based on the geometric dimensions of the Heat exchanger and the working fluid properties, the determination of air velocity from $0.32[\mathrm{~m} / \mathrm{s}]$ to $1.72[\mathrm{~m} / \mathrm{s}]$ has been made possible. With the increase of air velocity is increased the coefficient of heat convection from the air side. Figure 8 presents the Reynolds number from the fins surfaces by changing the air flow. As can be seen from Figure 8, the change of air flow in the value of Reynolds number is linear. As much higher the Reynolds number to be the value of heat exchanged between working fluids will be greater. 


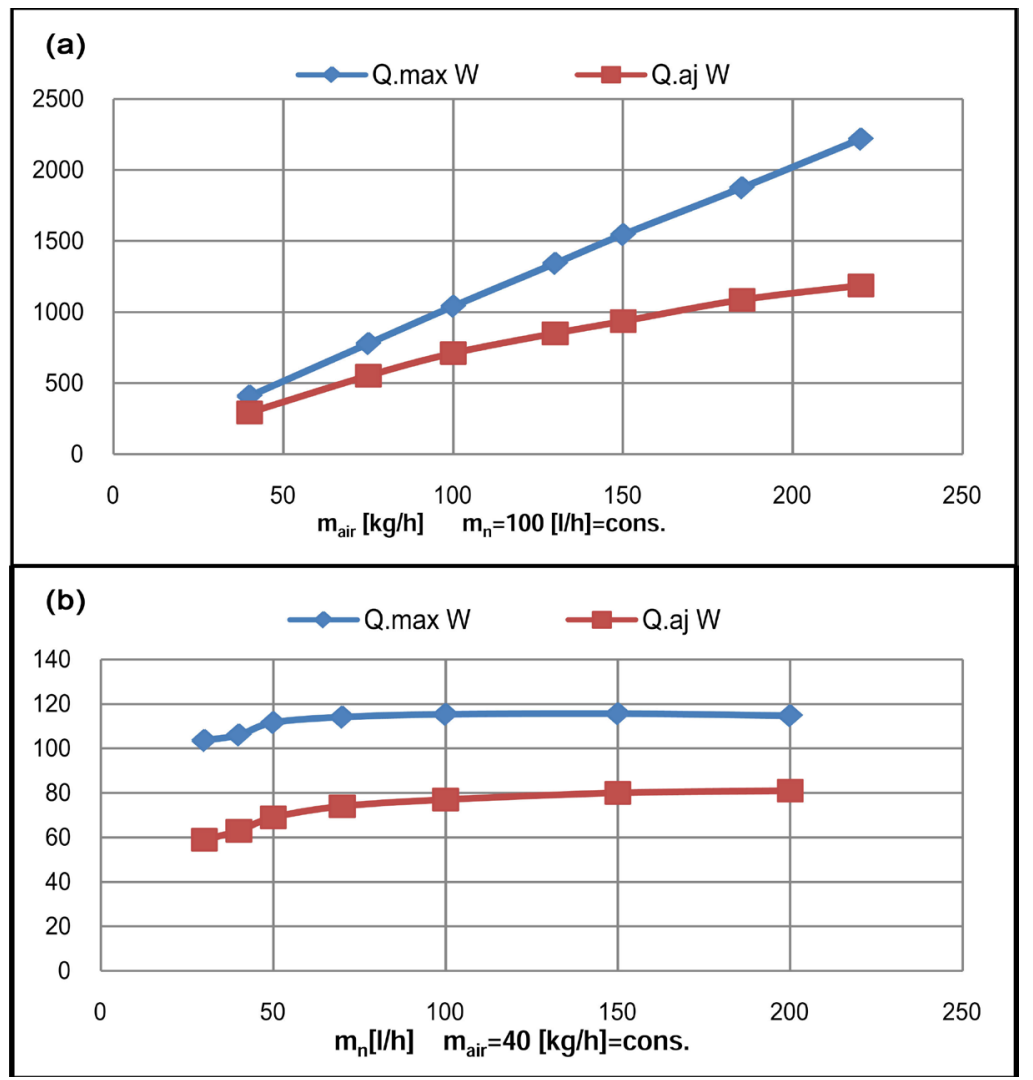

Figure 4. Real and maximal heat transferred in a heat exchanger, by changing the flow mass of working fluids.

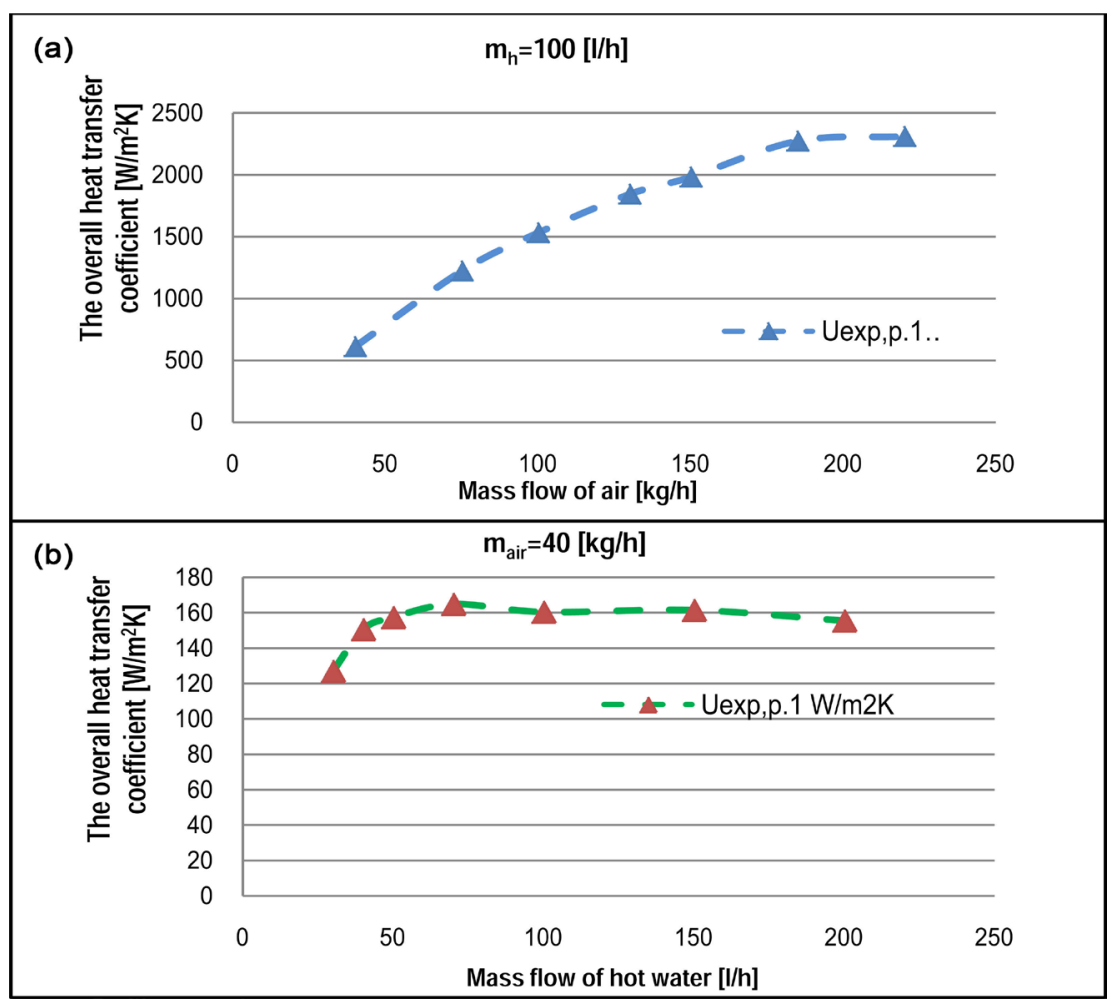

Figure 5. The overall heat transfer coefficient determined experimentally depending on the mass flow of working fluids. 


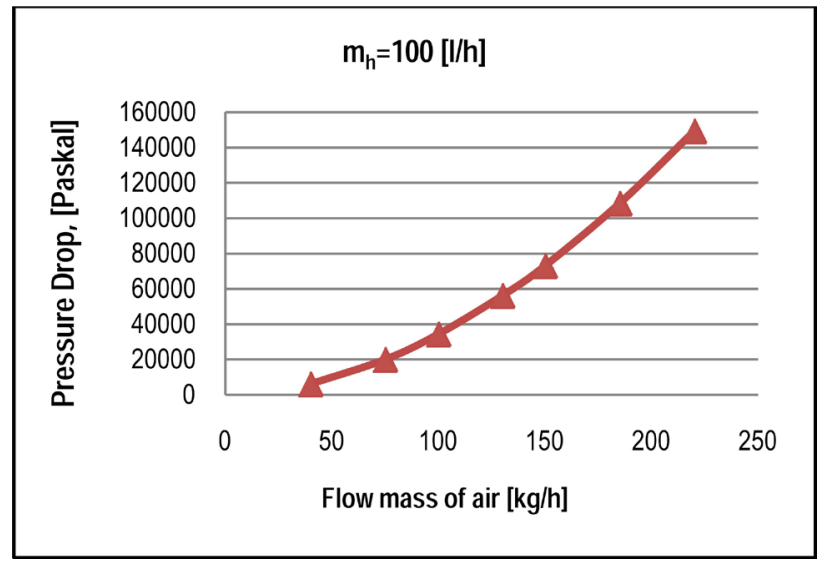

Figure 6. Pressure drop from the air side of the heat exchanger by changing the mass flow of air.

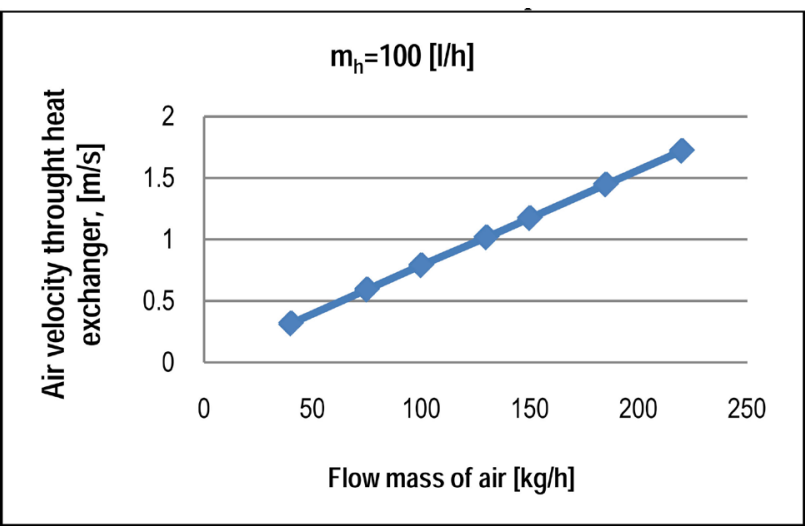

Figure 7. Air velocity from the air side of a heat exchanger by changing the mass flow of air.

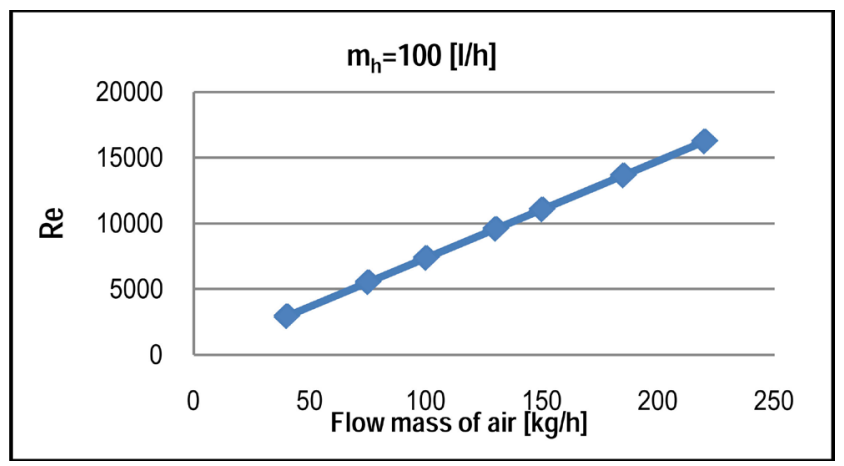

Figure 8. Reynolds number from the air side of a heat exchanger by changing the mass flow of air.

\section{Conclusions}

One of the key parameters in increasing the plate fins heat exchanger performance is to change the mass flow of working fluids. Figure 3 shows the effect of changing the flow of working fluids to the overall heat transfer efficiency. From this figure, it has been shown that for unchanged flow mass of hot water, but for a variable mass flow of air by the side of a heat exchanger with fins surfaces, the 
efficiency of the heat exchanger is reduced. This has happened as a result of short contact between working fluids and the inability that air to absorb the heat from the mass flow of hot water.

The result of increased airflow is the impossibility of achieving desired cooling (a case presented in the automotive industry that has caused the rising of engine temperature). The opposite happens when $\mathrm{m}_{\text {air }}=$ cons, but changes the mass flow of hot water by causing the heat exchanger efficiency to increase. Furthermore, from (Figure 4) it is concluded that the actual and maximal heat transferred in a heat exchanger for $\mathrm{m}_{\text {air }} \neq$ cons and $\mathrm{m}_{\mathrm{h}}=$ cons, have values much higher than the case when $\mathrm{m}_{\mathrm{h}} \neq$ const and $\mathrm{m}_{\text {air }}=$ const. This means that the greatest effect of the heat transferred in heat exchanger air-water is the change of air flow from the fins surfaces.

In addition, the overall efficiency of heat transfer coefficient determined experimentally varies considerably by changing the air flow from the side with fins surfaces and a small change is observed if the mass flow of hot water is changed (Figure 5).

\section{References}

[1] Shah, R.K. and Sekulic, D.P. (2003) Fundamentals of Heat Exchanger Design. Wiley.

[2] Kakaç, S. and Liu, H. (2002) Heat Exchangers, Selection, Rating and Thermal Design. CRC Press, Boca Raton.

[3] Tharumarimurugan, M. and Kannadasan, T. (2009) Simulation Studies on Plate Type Heat Exchanger Using ANN. Internacional Journal of Chemical Tech Research, 349-354.

[4] Alur, S. (2012) Experimental Studies on Plate Fin Heat Exchangers. Doctoral Dissertation, National Institute of Technology, India.

[5] Nabadi, H. (2008) Optimal Pin Fin Heat Exchanger Surface. Doctoral Dissertation, School of Sustainable Development of Society and Technology.

Submit or recommend next manuscript to SCIRP and we will provide best service for you:

Accepting pre-submission inquiries through Email, Facebook, LinkedIn, Twitter, etc. A wide selection of journals (inclusive of 9 subjects, more than 200 journals)

Providing 24-hour high-quality service

User-friendly online submission system

Fair and swift peer-review system

Efficient typesetting and proofreading procedure

Display of the result of downloads and visits, as well as the number of cited articles

Maximum dissemination of your research work

Submit your manuscript at: http://papersubmission.scirp.org/

Or contact wjet@scirp.org 